\title{
The Use of Continuous Ketamine for Analgesia and Sedation in Critically Ill Patients with Opioid Abuse: A Case Series
}

\author{
Cierra N. Treu ${ }^{1,2 *}$, Christine M. Groth ${ }^{1}$, Jignesh H. Patel ${ }^{1}$ \\ 1 University of Rochester Medical Center, Rochester, NY, USA \\ 2 SBH Health System, Bronx, New York, USA
}

\begin{abstract}
Managing pain and agitation in patients with opioid abuse is becoming more common in intensive care units. Tolerance to commonly used agents is often observed, leading to inadequate pain control and increased agitation. Ketamine's unique mechanism of action and opioid-sparing effects make it an ideal agent for patients with suboptimal response to opioid therapy.

This report describes our experience using continuous ketamine infusions for analgesia and sedation in four mechanically ventilated patients with histories of opioid abuse that had suboptimal response to standard therapy. Ketamine was successful in improving analgesia and sedation in three patients while reducing the need for other analgesics and sedatives with minimal adverse effects.

Continuous ketamine infusions may be useful to facilitate mechanical ventilation in patients with histories of opioid abuse with minimal toxicity. More information is needed on the optimal dose and titration parameters.
\end{abstract}

Keywords: critical care, ketamine, substance abuse, analgesia, sedation

Received: 25 July 2017 / Accepted: 22 September 2017

\section{INTRODUCTION}

Opioid prescribing in the United States remains at an all-time high with an estimated two million people presenting with opioid use disorders [1]. Providing adequate pain control/sedation to facilitate mechanical ventilation (MV) in these patients is difficult since they are often tolerant to typical doses of analgesics and sedatives. This has lead providers to explore nontraditional agents like ketamine for both analgesia and improved sedation despite limited supporting data [2]. Presented here are four cases of continuous ketamine as an adjunctive analgesic/sedative in MV patients with a history of opioid abuse. All four of these cases presented to the University of Rochester Medical Center (Rochester, NY, USA).

\section{Presentation of the Case Series}

\section{Case 1}

A 47-year-old female with a history of human immunodeficiency virus, nonalcoholic steatohepatitis, breast cancer, schizophrenia and opioid abuse on buprenorphine-naloxone, presented to the emergency department (ED) with acute respiratory distress syndrome, pneumonia, septic shock, acute kidney injury (AKI), and worsening hepatic impairment. She required vasopressors and significant ventilator support ( $\mathrm{FiO} 260 \%$, PEEP 16). She was given fentanyl $(250 \mathrm{mcg} / \mathrm{hr})$ and $\mathrm{mi}-$ dazolam $(4 \mathrm{mg} / \mathrm{hr})$ along with multiple boluses to facilitate MV. She continued to be encephalopathic with documented Riker Sedation-Agitation Scale (SAS) scores of 6 and non-verbal pain scores (NVPS) of 7. 
Ketamine $(0.1 \mathrm{mg} / \mathrm{kg} / \mathrm{hr})$ was started in an attempt to control her pain and agitation and alleviate further haemodynamic compromise. It was titrated to $0.65 \mathrm{mg} /$ $\mathrm{kg} / \mathrm{hr}$ over six hours, with three concurrent boluses of $0.25-0.5 \mathrm{mg} / \mathrm{kg}$. After seventeen hours, the dose of fentanyl was decreased to $150 \mathrm{mcg} / \mathrm{hr}$, and midazolam and norepinephrine were discontinued. The patient was no longer agitated and the SAS was recorded as 3 . She refuted being in pain and was alert, oriented, followed commands and interacted appropriately with her family. After discussing goals of care with the family and providers, the decision to pursue comfort care measures was made.

\section{Case 2}

A 47-year-old male with a history of metastatic lung cancer and polysubstance abuse, including cocaine, heroin and alcohol, presented after a motor vehicle collision (MVC) with subarachnoid haemorrhage and multiple fractures. He had been intubated for airway protection by Emergency Medical Services (EMS). At the time of ED arrival, he had six fentanyl $100 \mathrm{mcg} / \mathrm{hr}$ patches on his back which were removed and replaced by a fentanyl infusion (100 mcg/hr). Given his extremely high opioid use and agitation (SAS 5 and NVPS 8), the physician in charge of the acute pain service was consulted and ketamine was recommended. A bolus dose of ketamine ( 0.25 $\mathrm{mg} / \mathrm{kg}$ ), was given IV with excellent effect so a continuous infusion was started at $0.5 \mathrm{mg} / \mathrm{kg} / \mathrm{hr}$ and increased to $0.8 \mathrm{mg} / \mathrm{kg} / \mathrm{hr}$. The patient's SAS and NVPS scores decreased to 3 and 4 respectively. Over the course of the day the patient required multiple bedside interventions such as wound irrigation, laceration repair, lower extremity splinting, chest tube insertion, and central and arterial line placement, so a continuous midazolam infusion was started $(2 \mathrm{mg} / \mathrm{hr})$ and fentanyl was increased $(300 \mathrm{mcg} /$ $\mathrm{hr})$. The ketamine was discontinued after 3 days due to an increase in intracranial pressure (ICP). Subsequently, midazolam was increased to $4 \mathrm{mg} / \mathrm{hr}$ and fentanyl to 500 $\mathrm{mcg} / \mathrm{hr}$, in addition to requiring hourly boluses. Over the next four days, the midazolam was titrated off and the fentanyl was decreased to $125 \mathrm{mcg} / \mathrm{hr}$. In addition to this, he was transitioned to fentanyl patches $500 \mathrm{mcg} / \mathrm{hr}$ q48h, oxycodone $30 \mathrm{mg}$ q4h, gabapentin $1200 \mathrm{mg}$ q $8 \mathrm{~h}$, and acetaminophen $1000 \mathrm{mg} \mathrm{q} 8 \mathrm{~h}$. The fentanyl infuson was discontinued when he was extubated, four days later. He remained on fentanyl patches $500 \mathrm{mcg} / \mathrm{hr}$ and gabapentin $1200 \mathrm{mg} \mathrm{q} 8 \mathrm{~h}$, as the oxycodone was slowly transitioned to "as needed doses" only. He was discharged to a brain injury rehabilitation center.

\section{Case 3}

A 60-year-old male with a history of chronic obstructive pulmonary disease, spinal stenosis, and chronic pain presented with encephalopathy, AKI, transaminitis, rhabdomyolysis, and sepsis secondary to pneumonia. He was intubated for airway protection upon arrival to the ED.

Outpatient records indicated the use of unknown amounts of fentanyl $100 \mathrm{mcg} / \mathrm{hr}$ and $50 \mathrm{mcg} / \mathrm{hr}$ patches, oxycodone acetaminophen 10-325 mg tablets 2 tablets q6h, and diazepam $5 \mathrm{mg}$ tablets q12h. Fentanyl (75 $\mathrm{mcg} / \mathrm{hr})$, propofol $(20 \mathrm{mcg} / \mathrm{kg} / \mathrm{min})$ and enteral diazepam were initiated for post-intubation sedation with satisfactory effect (SAS 2). However, any attempt to lighten sedation resulted in hyperactive delirium with an increase in the SAS to 6. Dexmedetomidine $(1.5 \mathrm{mcg} / \mathrm{kg} / \mathrm{hr}$ ) was used to reduce the amounts of the other sedatives, but agitation persisted (SAS 6). To counteract this, the fentanyl dose was increased to $175 \mathrm{mcg} / \mathrm{hr}$. Quetiapine $50 \mathrm{mg} \mathrm{q} 12 \mathrm{~h}$ and haloperidol 5 $\mathrm{mg}$ IV $\mathrm{q} 2 \mathrm{~h}$ as needed were started to treat the patient's hyperactive delirium. Any attempts in decreasing the fentanyl infusion resulted in signs of opioid withdrawal and hyperactive delirium. Dexmedetomidine did not appear to be providing any benefit so it was discontinued and fentanyl (250 mcg/hr) and quetiapine (150 mg q12h) were increased to the stated doses. Propofol was reinitiated without success with the SAS remaining at 6. On hospital day 11, propofol was changed to ketamine $(0.5 \mathrm{mg} / \mathrm{kg} / \mathrm{hr})$ and dexmedetomidine $(1.5 \mathrm{mcg} /$ $\mathrm{kg} / \mathrm{hr}$ ) was restarted to help with the sympathomimetic effects of opioid withdrawal. Within 24 hours, the drug regimen was reduced to fentanyl $(100 \mathrm{mcg} / \mathrm{hr})$, ketamine $(0.1 \mathrm{mg} / \mathrm{kg} / \mathrm{hr})$, and dexmedetomidine $(0.5 \mathrm{mcg} /$ $\mathrm{kg} / \mathrm{hr}$ ). His heart rate (HR) and blood pressure (BP) normalized, his SAS scores were 3, and his intensive care unit delirium screening checklist (ICU-DSC) was negative for delirium. He had increased oral secretions, which required frequent suctioning. Treatment was reverted to the provision of fentanyl patches $(100 \mathrm{mcg} /$ hr) and he was slowly titrated off ketamine and dexmedetomidine over the next 3 and 6 days respectively. The patient was weaned off opioids entirely before discharge and has remained opioid-free.

\section{Case 4}

A 32-year-old male with a history of atrial fibrillation (AF), hypertension, morbid obesity, obstructive sleep apnea, asthma, and polysubstance abuse (heroin, eth- 
anol) presented to the ED after suffering a MVC. He was unresponsive and was intubated by EMS for airway protection. On arrival to the $\mathrm{ED}$, the patient was agitated (SAS 6) so fentanyl ( $400 \mathrm{mcg} / \mathrm{hr}$ ) and midazolam (9 mg/hr) were prescribed. On hospital day 2 , he developed AF with a rapid ventricular response for which diltiazem infusion of $12.5 \mathrm{mg} / \mathrm{hr}$ was initiated without effect. However, tachycardia resolved subsequent to the administration of fentanyl/midazolam boluses, suggestive of possible opioid withdrawal syndrome.

Due to persistent agitation (SAS 7) despite high rates of fentanyl $(300 \mathrm{mcg} / \mathrm{hr})$ and midazolam $(9 \mathrm{mg} / \mathrm{hr})$ with multiple boluses, a propofol infusion of $20 \mathrm{mcg} /$ $\mathrm{kg} / \mathrm{min}$ was started on hospital day 2 . Over the next 12 hours, the midazolam drip was titrated off and he remained on fentanyl $(400 \mathrm{mcg} / \mathrm{hr})$ and propofol $(20$ $\mathrm{mcg} / \mathrm{kg} / \mathrm{min}$ ). On hospital day 4 , the patient again became increasingly agitated (SAS 6). Due to concern for suspected propofol related infusion syndrome, he was transitioned from propofol to midazolam $(7 \mathrm{mg} /$ $\mathrm{hr})$, and dexmedetomidine $(1.5 \mathrm{mcg} / \mathrm{kg} / \mathrm{hr})$ infusions. Despite these changes, the patient continued to have a SAS scores of 6 . On hospital day 5 , he was started on ketamine with a bolus dose of $0.4 \mathrm{mg} / \mathrm{kg}$ followed by a continuous infusion of $0.4 \mathrm{mg} / \mathrm{kg} / \mathrm{hr}$. He continued to have SAS scores of 5 to 7 so ketamine was titrated to $1.5 \mathrm{mg} / \mathrm{kg} / \mathrm{hr}$ over the next day and the midazolam was titrated down to $2 \mathrm{mg} / \mathrm{hr}$. After these adjustments his SAS scores were consistently around 3 and he was able to follow simple commands and denied pain, but was noted to have increased oral secretions.

On day 9 he became acutely agitated again with a SAS score of 6 . Ketamine and midazolam were increased immediately to $1.7 \mathrm{mg} / \mathrm{kg} / \mathrm{hr}$ and $8 \mathrm{mg} / \mathrm{hr}$, respectively. Approximately twenty-four hours later, the patient became increasingly agitated again and bit through his endotracheal (ET) tube. During the ET tube exchange, the patient was breathing spontaneously and the staff in charge concluded that it was safe to extubate. Ketamine and midazolam were discontinued immediately, but the fentanyl and dexmedetomidine infusions were continued for 18 hours due to the patient's persistent agitation and hallucinations. He did not require reintubation and was prescribed buprenorphine $8 \mathrm{mg}$ sublingual every 12 hours as needed and a clonidine patch $0.1 \mathrm{mg} / 24 \mathrm{hr}$, plus $0.1 \mathrm{mg}$ orally every 12 hours as needed. He was discharged to the chemical dependency rehabilitation centre five days later and follow-up consultation was arranged.

\section{DISCUSSION}

Inadequate pain and agitation control are common in critically ill opioid-tolerant patients, and high doses of analgesics and sedatives are often required to facilitate MV. This may lead to oversedation and adverse drug events (ADEs) that require the patient to be maintained on a ventilator for prolonged periods of time. Ideally, a sedative with analgesic properties that could reduce the dose of narcotics or sedatives, while keeping patients awake and calm, would be of benefit in these difficult cases.

Ketamine has a unique mechanism of action with analgesic properties even at sub-anaesthetic doses of less than $0.3 \mathrm{mg} / \mathrm{kg} \mathrm{IV}$, due to $\mathrm{N}$-methyl-D-aspartate (NMDA) receptor inhibition [3]. Chronic consumption of opioids increases NMDA activity leading to opioid tolerance. By blocking activation of the NMDA receptor, ketamine reverses opioid tolerance and prevents long-term central desensitization. Ketamine has gained popularity in perioperative pain management settings due to its opioid-sparing effects and prevention of chronic pain. In opioid-tolerant patients, ketamine use improved pain scores at one hour and reduced narcotic consumption in the first few days following surgery, as well as out to 6 weeks post-operative with no ADEs [4-6]. Although the evidence in the literature is limited, it suggests there may be a place for ketamine in analgesia management in opioid-tolerant patients.

Ketamine has recently made a resurgence in ICUs as providers are looking for alternatives to benzodiazepine-based sedation, but data on how to use this medication appropriately and safely are sparse. Patanwala et al. (2017) published a review evaluating the role of sustained ketamine infusions as used in ICUs for analgesia/sedation management compared to traditional opioid-based regimens [7]. Data was included from randomized control trials, observational studies, and case reports/series. Ketamine use was associated with decreased opioid consumption, improved gastrointestinal motility and had no detrimental impact on cardiovascular or cerebral haemodynamics. These authors concluded that ketamine infusions appear to have opioid-sparing effects and can be used in patients refractory to standard regimens. These findings are consistent with the Society of Critical Care Medicine (SCCM) sedation guidelines which acknowledge ketamine as an option in reducing opioid requirements or ADEs [8]. At our institution, we have guidelines for analgesia/se- 
dation management for MV patients that parallel the SCCM recommendations. The procedure that is followed is to treat pain by the use of intermittent doses of drugs followed, if necessary, by continuous infusions. Analgosedation is used to treat agitation before sedatives. We use validated scoring tools to assess for pain and agitation (NVPS, SAS), attempt daily sedation holidays and dose reductions, and utilize ICU-DSC to screen patients for delirium. Our goal is to keep patients comfortable, but interactive. We specifically utilized ketamine for its analgesic properties in these four cases because of the patients' history of chronic opioid use and the difficulty sedating them using our institution's standard guidelines.

All four patients were either heavily sedated or severely agitated with traditional therapies. Ketamine use resulted in decreased pain scores and opioid requirements and maintained sedation within the SAS range of 3-4, in three of the four cases. In Case 2, when ketamine was discontinued, pain scores increased which was indicative of it providing significant analgesia. Ketamine may have helped reduce opioid consumption in the long-term, as implied in Case 3, when the patient was discharged opioid-free.

Ketamine offered a haemodynamic advantage in Case 1, allowing for discontinuation of vasopressors. Ketamine is known to have sympathomimetic effects leading to increases in $\mathrm{BP}$ and $\mathrm{HR}[3,7,9,10]$. No significant haemodynamic instability was recorded in any of the patients, however they lacked significant cardiac histories and any potential cardiac changes could have been masked by dexmedetomidine $[11,12]$.

Ketamine use was unsuccessful in Case 4. It's possible the patient's agitation was due to withdrawal from multiple substances and not inadequate pain control since he denied pain. His agitation could have been attributable to hyperactive delirium exacerbated by ketamine. Ketamine may cause delirium, confusion, agitation, nightmares, and hallucinations which are more common in larger doses $[3,6]$. It's also associated with alterations in perception upon discontinuation [6]. Hallucinations were experienced by the patient in Case 4 after ketamine was discontinued. In Cases 1 and 3 , the confused state of delirium improved when better pain control was achieved and as opioid withdrawal symptoms resided.

Concern for increased ICP led to ketamine being discontinued in Case 2. Elevations in ICP were historically associated with ketamine use, but recent literature reports have discredited this theory. Most published data indicate ketamine has little effect on ICP and cerebral perfusion pressure is typically maintained or increased with no adverse effects on neurological outcome or mortality $[7,13,14]$. Therefore, the increase in ICP seen in our patient was unlikely to have resulted from ketamine use.

Hypersalivation, a well-known ADE of ketamine [3], was seen in two of our cases. Typically it can be managed with antisialagogues or antimuscarinic agents. In the reported cases, frequent suctioning was required without concomitant drug therapy.

\section{CONCLUSIONS}

Continuous ketamine infusions may be useful in achieving adequate sedation and analgesia in MV patients with histories of opioid abuse who do not respond to traditional drug regimes. It appears to be safe and well tolerated, but more information is needed to determine the optimal doses and titration parameters.

\section{CONFLICTS OF INTEREST}

None declared.

\section{GUNDING}

This research did not receive any specific grant from funding agencies in the public, commercial, or not-forprofit sectors.

\section{REFERENCES}

1. Schuchat A, Houry D, Guy GP. New Data on Opioid Use and Prescribing in the United States. JAMA. Published online July 06, 2017. doi:10.1001/jama.2017.8913

2. Vadivelu N, Mitra S, Kaye AD, et al. Perioperative analgesia and challenges in the drug-addicted and drug-dependent patient. Best Pract Res Clin Anaesthesiol. 2014;28:91-101.

3. Gorlin AW, Rosenfeld DM, Ramakrishna H. Intravenous subanaesthetic ketamine for perioperative analgesia. J Anaesthesiol Clin Pharmacol. 2016;32:160-167.

4. Haller G, Waeber JL, Infante NK, et al. Ketamine combined with Morphine for the Management of Pain in an Opioid Addict. Anesthesiology. 2002;96(5):1265-1266.

5. Urban MK, Ya Deau JT, Wukovits B, et al. Ketamine as an Adjunct to Postoperative Pain Management in Opioid-Tolerant Patients After Spinal Fusions: A Prospective Randomized Trial. HSS J. 2008;4:62-65. 
152 The Journal of Critical Care Medicine 2017;3(4)

6. Loftus RW, Yeager MP, Clark JA, et al. Intraoperative Ketamine Reduces Perioperative Opiate Consumption in Opiatedependent Patients with Chronic Back Pain Undergoing Back Surgery. Anesthesiology. 2010;113:639-646.

7. Patanwala $A E$, Martin RA, Erstad BL. Ketamine for Analgosedation in the Intensive Care Unit: A Systematic Review. J Intensive Care Med. 2017;32(6):387-395.

8. Barr J, Fraser GL, Puntillo K, et al. Clinical practice guidelines for the management of pain, agitation, and delirium in adult patients in the intensive care unit. Crit Care Med. 2013;41:263306.

9. Miller AC, Jamin CT, Elamin EM. Continuous intravenous infusion of ketamine for maintenance sedation. Minerva Anestesiol. 2011;77(8):812-820.

10. Whitman CB, Rhodes HM, Tellor BR, et al. Continuous Infusion Ketamine for Adjunctive Sedation in Medical Intensive Care
Available online at: www.jccm.ro

Unit Patients: A Case Series. Enliven: J Anesthesiol Crit Care Med. 2015;2(5):1-5.

11. Tobias JD. Dexmedetomidine and ketamine: An effective alternative for procedural sedation? Pediatr Crit Care Med. 2012;13:423-427.

12. Christ G, Mundigler G, Merhaut C, et al. Cardiac transplantation: a prospective comparison of ketamine and sufentanil for anesthetic induction. J Cardiothorac Anesth. 1989;3(4):389395.

13. Zeiler FA, Teitelbaum J, West M, et al. The ketamine effect on ICP in traumatic brain injury. Neurocrit Care. 2014;21(1):16373.

14. Cohen L, Athaide V, Wickham ME, et al. The Effect of Ketamine on Intracranial and Cerebral Perfusion Pressure and Health Outcomes: A Systematic Review. Ann Emerg Med. 2015;65(1):43-51. 